\title{
Discussão sobre a Situação dos Depósitos de Lixo no Pontal do Paranapanema - SP
}

Discussion on the Situation of Garbage Deposits in Pontal of Paranapanema - SP

Discusión sobre la situación de los depósitos de Lixo no Pontal do Paranapanema - SP

\author{
Lucas Henrique Pereira Silva \\ Mestrando, Unoeste, Brasil. \\ lucashpsilva@outlook.com

\section{Jacqueline Roberta Tamashiro \\ Mestra, Unoeste, Brasil. \\ arquiteta.jtamashiro@hotmail.com}
Natália Gerlack Guerrer
Mestranda, UEM, Brasil. nataliagerlack@gmail.com

Fabrícia Mitiko Ikuta Professora Mestre, IFSP, Brasil. fabriccia@gmail.com 


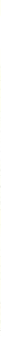

\section{RESUMO}

A Política Nacional dos Resíduos Sólidos (PNRS) representou um grande avanço na questão da correta destinação dos resíduos sólidos no Brasil, apesar disso os municípios têm tido grandes dificuldades de se adequarem e por isso o prazo que inicialmente era 2 de agosto de 2014 foi estendido. O Pontal do Paranapanema é uma região marcada pela degradação do ambiente natural e falta de preocupação com o meio de maneira que restou apenas $7 \%$ da vegetação nativa. Buscando conhecer a situação da infraestrutura e de serviço dos depósitos de lixo dentro da região este trabalho apresenta a situação e discute as considerações de pesquisadores contemporâneos com relação aos depósitos de lixo. O trabalho ainda trata do fechamento do lixão de Pirapozinho, SP e da implantação de um aterro sanitário consorciado por alguns municípios do Pontal.

PALAVRAS-CHAVE: Depósito de lixo, Pontal do Paranapanema, Resíduo sólido

\section{ABSTRACT}

The Solid Waste National Policy (PNRS) represents a major advance in correct destination of solid wastes in Brazil but the municipalities have been difficulties in implementing and so the deadline that was August 2, 2014 was increased. The Pontal do Paranapanema is a region marked by the degradation of the natural environment and the lack of concern for the environment that is why left over only $7 \%$ of the native vegetation. Looking for knowing about the situation of infrastructure and the service of the garbage deposits within the region this paper introduce the situation and discusses the considerations of contemporary researchers. The paper also deals with the closure of garbage deposit from Pirapozinho, SP and the implementation of a sanitary landfill jointly owned by some municipalities of Pontal.

KEYWORDS: Garbage deposits, Pontal do Paranapanema, Solid waste

\section{RESUMEN}

La Política Nacional de los Residuos Sólidos (PNRS) representó un gran avance en la cuestión de la correcta destinación de los residuos sólidos en Brasil, a pesar de que los municipios han tenido grandes dificultades de adecuarse y por eso el plazo que inicialmente era el 2 de agosto de 2014 fue extendido. El Pontal do Paranapanema es una región marcada por la degradación del ambiente natural y la falta de preocupación con el medio de manera que quedaba sólo el $7 \%$ de la vegetación nativa. Con el fin de conocer la situación de la infraestructura y de servicio de los depósitos de basura dentro de la región este trabajo presenta la situación y discute las consideraciones de investigadores contemporáneos con relación a los depósitos de basura. El trabajo todavía trata del cierre del basural de Pirapozinho, SP y de la implantación de un relleno sanitario consorciado por algunos municipios del Pontal.

PALABRAS-CHAVE: Deposito de basura, Pontal do Paranapanema, Residuos sólidos 


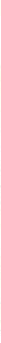

\section{INTRODUÇÃO}

A principal consequência da organização do homem em sociedades foi a geração e o aumento dos resíduos sólidos urbanos (RSU). A preocupação com esta questão ganhou maior evidência com o grande crescimento populacional, a densa população vivendo nas cidades e a urbanização desordenada que aconteceram após a revolução industrial. Deste período adiante, líderes mundiais têm refletido com maior atenção sobre este tema, o que culminou na ECO-92, onde no Rio de Janeiro um dos assuntos abordados foi o manejo sustentável dos resíduos sólidos.

Em harmonia com a ECO-92 e posteriormente com a Rio+20 é que o Brasil, ainda que tardiamente, após vinte anos de tramitação no Congresso, em 2010, aprovou a Lei 12.305 que instituiu a Política Nacional dos Resíduos Sólidos (PNRS), regulamentada pelo Decreto 7.404/10, que criou metas para eliminação dos lixões - até 02 de agosto de 2014. Entretanto, após não atender as metas, mais 4 anos foram incluídos ao prazo afim de que os municípios se adequassem (BRASIL, 2010; OLIVEIRA, 2015).

Algumas pesquisas realizadas sobre a região do Pontal do Paranapanema, trazem suas contribuições em relação a situação dos depósitos de lixo e fazem suas análises em relação as possibilidades e viés técnicos, econômicos e sociais que impedem a implantação efetiva dos aterros sanitários e os avanços representados pela PNRS (OLIVEIRA, 2015; OSCO, 2016; BUENO; LEAL, 2012; FAGUNDES, 2008). Felício (2016a) questiona se é viável e crível a extinção de todos os lixões para os municípios da Unidade de Gerenciamento dos Recursos Hídricos 22 (UGRHI22).

As maiores dificuldades encontradas pelos municípios para implantação dos aterros sanitários estão relacionadas a disponibilidade de áreas que atendam os critérios técnicos, legais, operacionais e socioeconômicos para sua implantação e também quanto a disponibilidade de recursos financeiros. A fim de transpor estes desafios é que existe a possibilidade dos municípios se organizarem em consórcios. Nos consórcios diversos municípios contribuem para implantação e manutenção do aterro sanitário independente dele estar localizado em uma cidade ou outra.

Este trabalho, apresenta como estudo de caso a situação dos depósitos de lixo na UGRHI - 22, bem como a discussão sobre suas potencialidades, fragilidades técnicas, operacionais e ambientais.

\section{METODOLOGIA}

A apresentação dos dados e discussão sobre as condições dos depósitos de lixo foi construída a partir da revisão bibliográfica de pesquisas que abordam a situação da gestão dos resíduos sólidos na Região do Pontal do Paranapanema, SP. A partir de então, foram realizadas visitas in loco ao lixão de Pirapozinho, SP, onde investigou-se as reais condições do local que fora mantido irregularmente durante tanto tempo. 
2015). Esta pré-seleção de áreas abrange critérios técnicos, socioeconômicos e pontuais - que podem gerar entraves políticos - de grande relevância e custo, sendo este último um dos fatores que impedem que as municipalidades consigam atender as demandas da PNRS.

Entre os critérios técnicos necessariamente analisados para implantação dos aterros sanitários estão a litologia e pedologia do local, uso e ocupação do solo, a proximidade com áreas urbanas, rios, rodovias entre outros que podem ser observados com maiores detalhes na Tabela 1 . Muitos destes critérios são também considerados para avaliação do Índice de Qualidade de Aterro de Resíduo - IQR, realizado anualmente pela Companhia Ambiental do Estado de São Paulo CETESB e publicado no Inventário Estadual de Resíduos Sólidos Urbanos.

Tabela 1: Características do local avaliadas nos aterros sanitários

\begin{tabular}{ccc}
\hline Categoria & Avaliação Positiva & Avaliação Negativa \\
\hline Proximidade de corpos d'água & $>200$ metros & $<200$ metros \\
\hline Proximidade de núcleos habitacionais & $>500$ metros & $<500$ metros \\
\hline Proximidade de aeródromos $^{1}$ & $>20$ quilômetros & $<20$ quilômetros \\
\hline Proximidade de rodovias & $>200$ metros & $<200$ metros \\
\hline Declividade do terreno & Entre 2\% e $8 \%$ & $2 \%>$ Declividade $>8 \%$ \\
\hline Profundidade do substrato rochoso & $>15$ metros & $<15$ metros \\
\hline Profundidade do lençol freático & $>3$ metros & $<3$ metros \\
\hline Permeabilidade do solo & Baixa & Alta \\
\hline Capacidade de Suporte do solo & Adequada & Inadequada \\
\hline Material para recobrimento & Suficiente & Insuficiente \\
\hline Qualidade do material para & Boa & Ruim \\
recobrimento & Suficiente & Insuficiente \\
\hline Isolamento Físico & Adequado & Inadequado \\
\hline Isolamento Visual & Adequado & Inadequado \\
\hline Acesso à frente de cargas &
\end{tabular}

Fonte: Os próprios autores

Diante à Tabela 2, dos 26 municípios que compõe o Pontal do Paranapanema apenas Presidente Venceslau não dispõe seus resíduos em aterros controlados ou lixões a céu aberto e nenhum dos depósitos de lixo apresentam sistemas de captação e tratamento do chorume e gases gerados. Toda esta problemática diz muito a respeito de como as lideranças municipais veem a

\footnotetext{
${ }^{1}$ Entende-se por aeródromo a área definida destinada à chegada, partida e movimentação de aeronaves enquanto que aeroporto é todo aeródromo público, dotado de instalações e facilidades para o apoio de aeronaves, embarque e desembarque de pessoas e cargas.
} 
importância do meio ambiente, já que entre as ameaças ao meio natural a disposição dos resíduos sólidos destaca-se entre as mais emergentes questões ambientais.

Tabela 2: Enquadramento dos municipios do Estado de São Paulo, quanto as condições de tratamento e disposição dos resíduos urbanos de 2011 a 2017 - UGRHI 22

\begin{tabular}{|c|c|c|c|c|c|c|c|c|c|}
\hline \multirow{3}{*}{ MUNICÍPIO } & \multirow{3}{*}{ RSU (t/dia) } & \multicolumn{7}{|c|}{ INVENTÁRIO } & \multirow{3}{*}{ ENQUADRAMENTO } \\
\hline & & 2011 & 2012 & 2013 & 2014 & 2015 & 2016 & 2017 & \\
\hline & & IQR & IQR & IQR & IQR & IQR & IQR & IQR & \\
\hline Anhumas & 2,32 & 8,5 & 8,5 & 9,2 & 8,4 & 8,4 & 8,2 & 8,6 & $A$ \\
\hline Caiuá & 1,53 & 8,5 & 7,3 & 7,3 & 7,5 & 7,5 & 7,2 & 4,7 & 1 \\
\hline Estrela Do Norte & 1,50 & 7,8 & 7,3 & 7,7 & 8,7 & 7,4 & 7,3 & 8,9 & A \\
\hline Euclides Da Cunha Paulista & 4,27 & 6,1 & 7,5 & 7,2 & 7,1 & 7,1 & 7,2 & 7,5 & A \\
\hline lepê & 5,04 & 7,1 & 7,2 & 7,2 & 5,1 & 7,9 & 7,4 & 8,5 & A \\
\hline Marabá Paulista & 1,75 & 8,2 & 7,7 & 7,3 & 7,1 & 7,3 & 7,8 & 7,3 & A \\
\hline Mirante do Paranapanema & 7,47 & 6,8 & 6,7 & 8,2 & 7,3 & 7,2 & 7,4 & 7,6 & A \\
\hline Nantes & 1,92 & 7,5 & 7,6 & 7,2 & 9,5 & 9,5 & 8,1 & 7,7 & A \\
\hline Narandiba & 2,41 & 7,1 & 8,5 & 8,5 & 7,2 & 7,4 & 7,2 & 8,9 & A \\
\hline Pirapozinho & 20,54 & 5,3 & 4,2 & 4,2 & 2,8 & 3,6 & 3,8 & 8,9 & A \\
\hline Presidente Bernardes & 7,27 & 7,1 & 7,1 & 7,1 & 9,0 & 7,2 & 7,1 & 8,6 & A \\
\hline Presidente Epitácio & 32,76 & 5,9 & 2,9 & 7,2 & 7,4 & 6,1 & 7,8 & 7,8 & A \\
\hline Presidente Prudente & 198,61 & 3,8 & 2,7 & 2,5 & 2,7 & 5,1 & 7,1 & 7,3 & A \\
\hline Presidente Venceslau & 30,27 & 6,2 & 6,1 & 7,1 & 8,4 & 9,4 & 7,5 & 3,9 & 1 \\
\hline Regente Feijó & 12,90 & 8,0 & 7,6 & 7,6 & 7,5 & 7,3 & 7,5 & 7,1 & A \\
\hline Rosana & 10,03 & 5,9 & 7,3 & 7,6 & 7,2 & 7,4 & 7,8 & 7,5 & A \\
\hline Sandovalina & 2,04 & 6,9 & 6,9 & 7,4 & 7,3 & 7,2 & 7,4 & 7,8 & A \\
\hline Santo Anastácio & 13,72 & 6,9 & 8,5 & 7,2 & 7,1 & 7,2 & 7,2 & 8,3 & $A$ \\
\hline Taciba & 3,68 & 7,2 & 6,7 & 8,0 & 8,5 & 7,1 & 7,3 & 7,7 & A \\
\hline Tarabai & 4,73 & 7,7 & 8,5 & 8,0 & 7,4 & 9,0 & 8,5 & 7,3 & A \\
\hline Teodoro Sampaio & 13,02 & 6,2 & 7,2 & 7,9 & 7,5 & 7,8 & 8,3 & 9,0 & A \\
\hline
\end{tabular}

Mediante à observação direta, utilizou-se uma rede de interação para qualificar os impactos que existem, atualmente, nos depósitos na UGRHI-22. As redes de interação consistem em um dos métodos descritos por Cremonez et al. (2014) para avaliação ambiental. Este método relaciona causa, condição e efeito dos impactos ambientais tendo como grande vantagem a fácil visualização dos impactos secundários.

A Figura 2 apresenta os processos e as ações de ordem diretas e indiretas e suas possíveis consequências. 


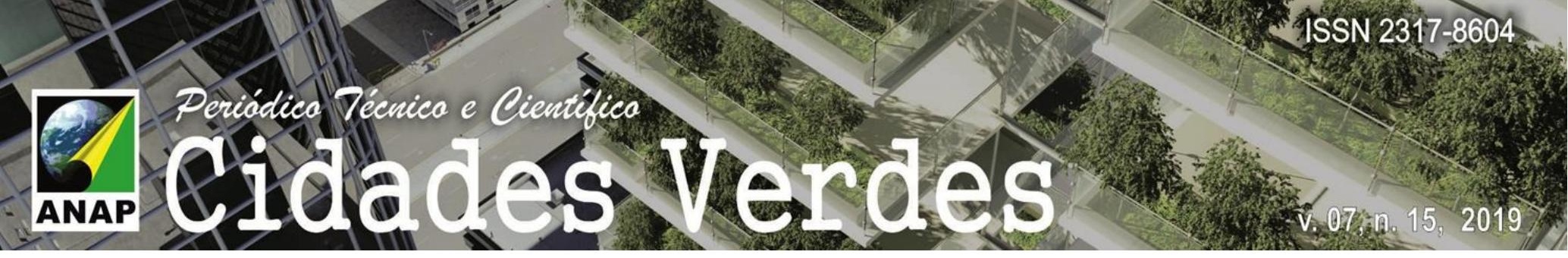

Figura 2: Rede de interação dos impactos ambientais dos depósitos de lixo do Pontal

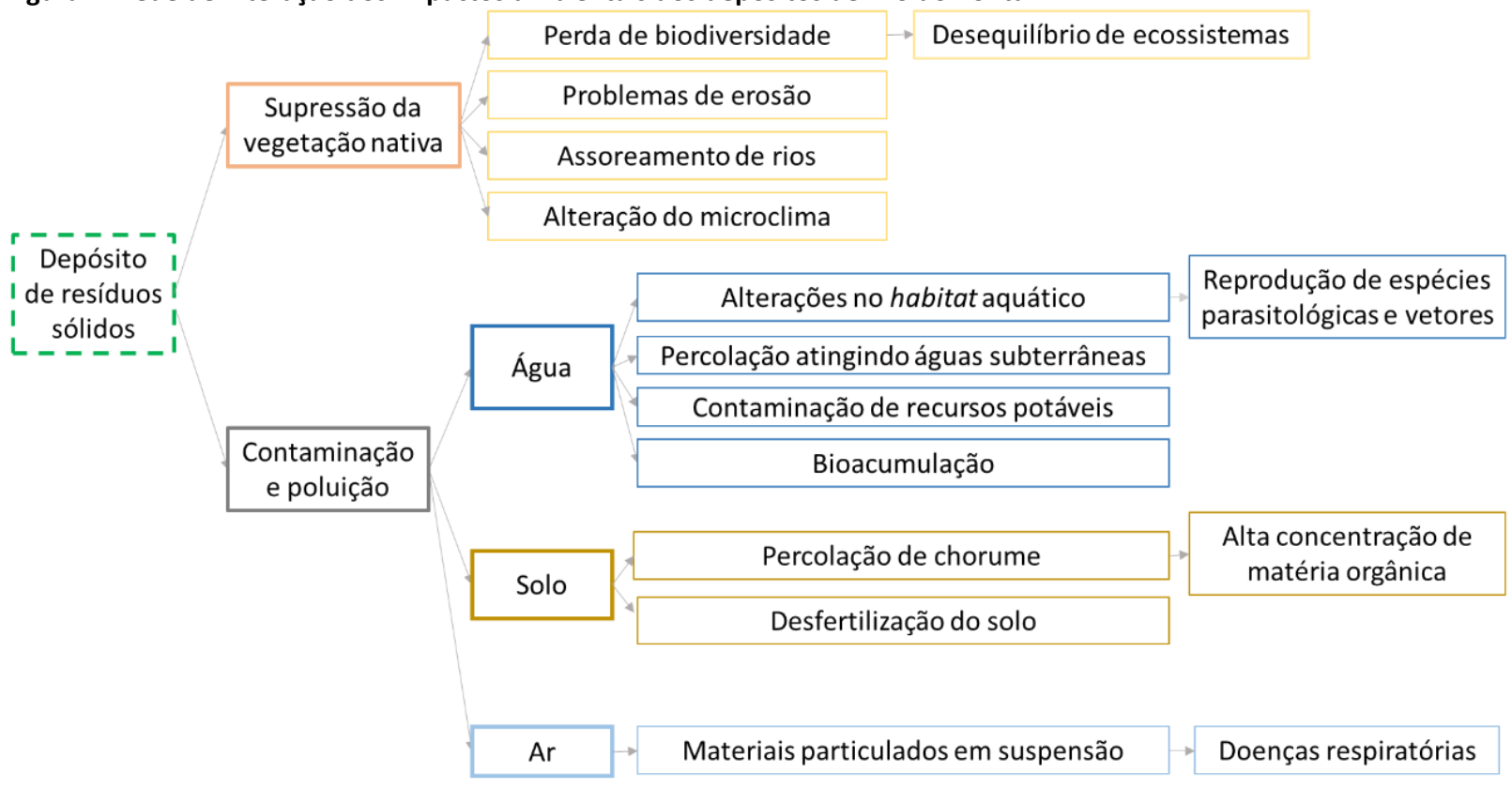

Fonte: Os próprios autores

Impactos diretos são aqueles causados pelas situações nocivas à saúde nos locais dos depósitos de lixo (CÂNDIDO et al., 2017). Além dos impactos diretos as condições de administração dos locais também acarretam em consequências às populações de áreas mais afastadas dos depósitos. Observa-se nos diversos impactos elencados na rede de interação através da contaminação de água potável e emissão de material particulado suspenso no ar (Figura 2).

Além da supressão nativa é necessário considerar que inúmeros serviços ecossistêmicos possam ser atingidos, podendo ocorrer diminuição de espécies vegetais nativas, aumento de processos erosivos, perda de produtividade, dispersão de poluentes, prejuízo a fertilidade do solo, queda dos índices de polinização com prejuízos a produção agrícola (BENNETT et al., 2009 e RIGUEIRA et al., 2013).

Tomando como exemplo as doenças respiratórias, indicada na Figura 2, causadas pela suspensão de materiais particulados (MP), Cesar, Nascimento e Carvalho Junior (2013), trazem que este cenário está associado a maior incidência de sintomas como tosse, dispneia respiratória e sibilância, principalmente em crianças até 10 anos de idade.

A proximidade de depósitos de lixo de corpos hídricos pode comprometer a saúde de populações relativamente longínquas, isto acontece porque a hidrografia se apresenta como fonte de água para infiltração e percolação do chorume (SANTOS, 2011; SANKOH; YAN; TRAN, 2013). O chorume possui alta concentração de matéria orgânica e poluentes inorgânicos que podem atingir cursos d'água ou percolar no solo atingindo águas subterrâneas que em áreas rurais normalmente são captadas em poços e podem causar doenças.

Analisando a localização dos depósitos na UGRHI-22, observa-se que no município de Nantes, o aterro está extremamente próximo a um corpo d'água assim como no município de lepê. Em 


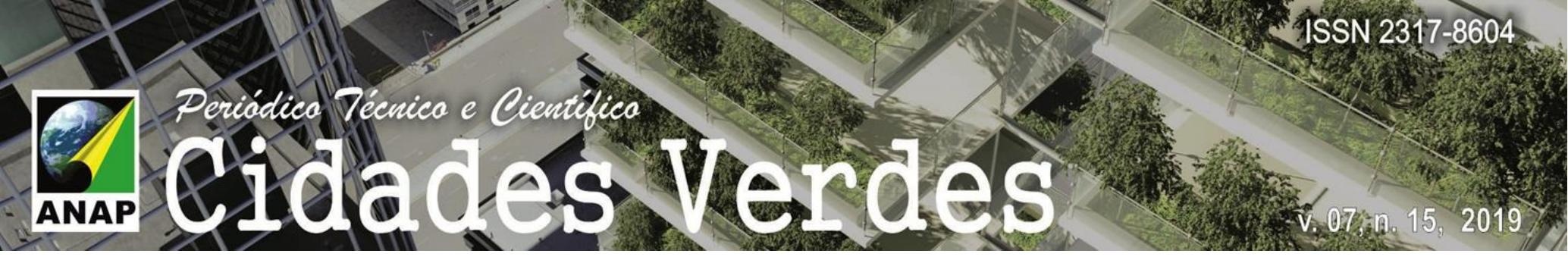

lepê o lençol freático aparenta ser raso e em Presidente Epitácio o depósito está a cerca de 500 metros da superfície do freático (OSCO, 2016). Ainda em relação à seguridade das águas superficiais e subterrâneas, a cidade de Pirapozinho apresenta uma nascente dentro da área compreendida pelo lixão.

O Novo Código Florestal Brasileiro, estabelece como Área de Preservação Permanente (APP), áreas que estão compreendidas dentro de um raio mínimo de 50 metros de nascentes - ainda que intermitentes - esta distância é tida como necessária para manutenção e garantia do sistema hídrico além de todos os benefícios garantidos por estes ecossistemas que abrangem a qualidade de vida no campo e nas zonas urbanas (SANKOH; YAN; TRAN, 2013).

Já em relação à geomorfologia do terreno, que trazem informações relacionadas a formação e espessura do solo, a investigação sobre a declividade na implantação dos aterros, se faz necessária, pois interferem na infiltração da água pluvial e na suscetibilidade a erosão (FERNANDES, 2012; FIGUEIREDO, 2013; ROMAGNOLI, 2018; GARCIA et al., 2013).

Geralmente, a espessura dos solos é inversamente proporcional à declividade do relevo, ou seja, quanto maior a declividade, menores são as condições de infiltração de água no solo e consequentemente o seu processo de formação é incipiente (OLIVEIRA, 2015, p.67) 


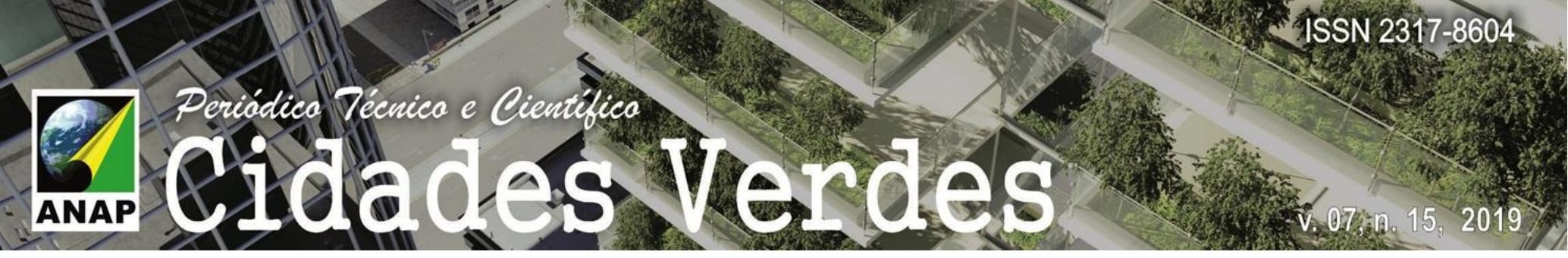

Além disso, o relevo pode influir indiretamente nas variações de temperatura, precipitação pluviométrica, ventos, etc. A Figura 3 apresenta o levantamento geomorfológico da Região do Pontal do Paranapanema.

Figura 3: Geomorfologia do Pontal do Paranapanema

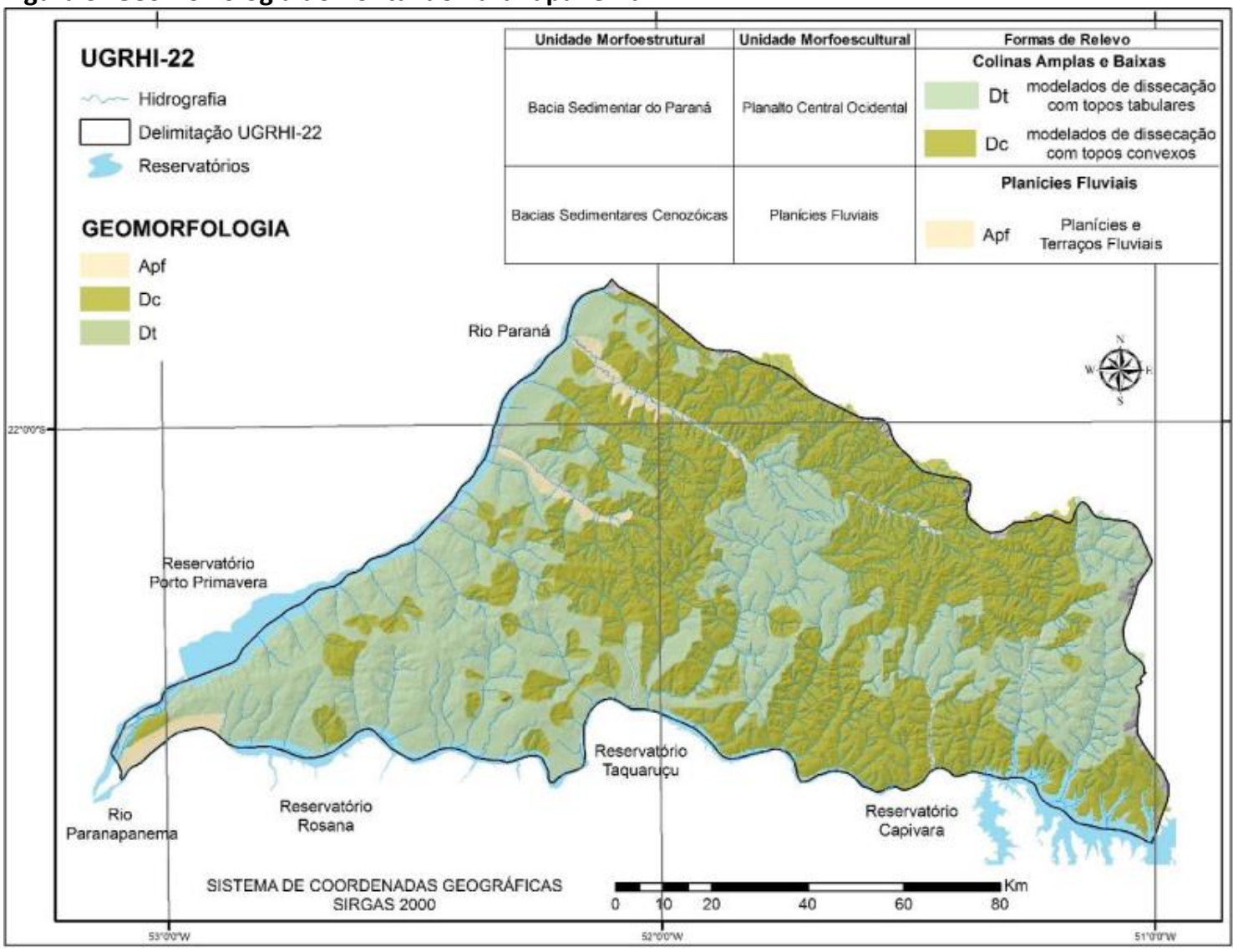

Fonte: Ross (1997); Romagnoli (2018)

Nas análises realizadas no Pontal, pode-se observar irregularidades em relação a declividade em diversos deles. Anhumas, Indiana, Pirapozinho são alguns dos depósitos que apresentam declividade acima da indicada. Em solos muito íngremes e descobertos - como é o caso dos depósitos de lixo - a água tende a escoar superficialmente e com velocidade acentuada, carregando partículas do solo e causando as erosões.

Em análise, percebeu-se que quando analisada a proximidade dos depósitos de lixo e áreas urbanas, grande quantidade deles se encontra em áreas que distam menos que dois quilômetros das cidades, são exemplos o de Estrela do Norte, e o de Euclides da Cunha, estes com distância de 0,4 e 1,4 quilômetros, respectivamente da cidade. A distância de dois quilômetros é descrita pela Organização Mundial da Saúde (WHO, 2000) como o raio de ação de contaminantes através da exposição dos recursos hídricos, já por via aérea, o raio de influência dos contaminantes cai 


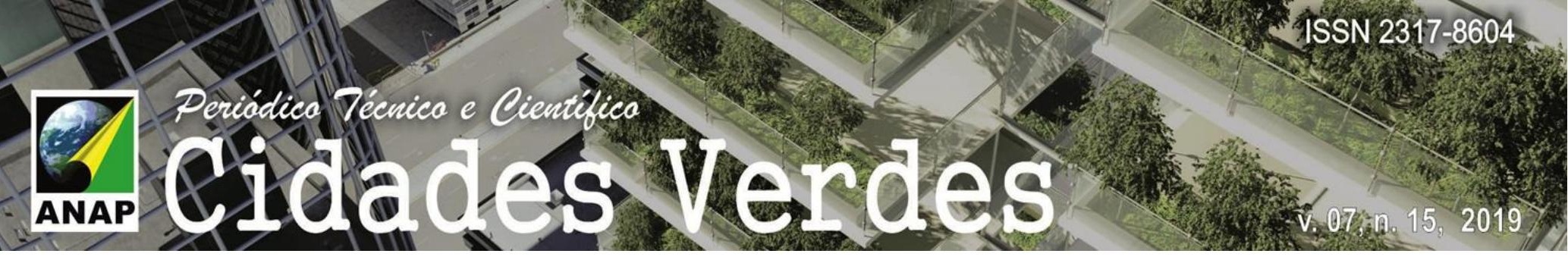

para um quilômetro. Depósitos próximos do perímetro urbano não só degradam o ambiente como impactam negativamente na saúde da população vive nas suas proximidades.

Outro ponto a ressaltar, é em relação ao isolamento físico e controle de tráfego de pessoas nos depósitos de lixo. Pelo risco iminente o acesso de pessoas não autorizadas a estas áreas podem facilitar a ocorrência de acidentes, contaminações e intoxicações, sobretudo quando há o livre acesso de crianças, como observado no município de Pirapozinho. $O$ isolamento da área como medida de controle, impede a presença de animais que, posteriormente, possam vir a transmitir zoonoses e outras doenças (ALMEIDA, 2018).

Outra atividade comumente observada, foram as deposições irregulares de resíduos, como aqueles advindos da construção civil, de industrias regionais, e hospitalares (resíduos de saúde). Nos aterros de Tarabai, Pirapozinho, Mirante do Paranapanema e lepê pode-se observar a presença de pelo menos um destes tipos de resíduo.

Além do isolamento, que impede a entrada de pessoas não autorizadas, é recomendado que os depósitos de lixo apresentem uma cortina de vegetação como barreira de isolamento. A presença da arborização ao redor da instalação contribui para amenizar o desconforto visual, estético e olfativo em função dos odores característicos que podem vir a surgir (SHINZATO, 2014; STUERMER; BROCANELI; VIEIRA, 2011). Em relação à implantação da cortina verde é mais fácil identificar os depósitos regionais adequados neste quesito. Apenas o de Estrela do Norte e Martinópolis apresentam a cortina verde, no entando em Martinópolis ainda é escassa a vegetação, corroborando com os dados de Osco (2016).

Além das condições de infraestrutura física e de implantação dos depósitos as práticas operacionais são um fator relevante na correta disposição final dos resíduos que podem, ou não, evitar a contaminação e a degradação do ambiente natural. Entre os parâmetros operacionais 
analisados estão as dimensões das valas, a presença de animais, a queimada de resíduos, entre outros que podem ser observados com mais detalhes na Tabela 2.

Tabela 2: Características operacionais avaliadas nos Aterros Sanitários

\begin{tabular}{lcc}
\multicolumn{1}{c}{ Categoria } & Avaliação Positiva & Avaliação Negativa \\
\hline Dimensão das valas & Adequado & Inadequado \\
\hline Recobrimento dos resíduos & Adequado & Inadequado \\
\hline Ocorrência de lixo descoberto & Não & Sim \\
\hline Presença de animais & Não & Sim \\
\hline Queimada de resíduos & Não & Sim \\
\hline Presença de moscas e odores & Não & Sim \\
\hline Presença de catadores & Não & Sim \\
\hline Criação de animais & Não & Sim \\
\hline Recebimento de resíduos industriais & Não & Sim \\
\hline Recebimento de resíduos hospitalares & Não & Sim \\
\hline Aproveitamento da área & Adequado & Inadequado \\
\hline Vida útil do terreno & $>5$ anos & $>2$ anos
\end{tabular}

Fonte: Os próprios autores

A dimensão das valas está intimamente ligada ao aproveitamento da área, a má execução destas compromete a vida útil do aterro sendo necessário o licenciamento e degradação de novas áreas. Não aproveitar corretamente o aterro é despender, desnecessariamente, do erário antes do previsto. Em Teodoro Sampaio, por exemplo, o aterro inicialmente projetado para que tivesse vida útil de 10 anos começou suas operações em 2001, e em 2007, uma outra área mesmo sem licenciamento - passou a ser utilizada, pois a primeira já havia atingido sua capacidade (FAGUNDES, 2008).

Ao final de cada dia de trabalho uma camada de terra ou material inerte, com espessura entre $15 \mathrm{~cm}$ e $20 \mathrm{~cm}$ deve ser adicionada sobre o resíduo compactado (CETESB, 2005). No dia seguinte, a camada é "raspada" para continuidade da disposição dos resíduos na mesma vala. Esta metodologia deve ser seguida a fim de evitar a disseminação de mal odores e a proliferação de vetores como moscas, ratos, baratas e aves. Notou-se que nos aterros da UGRHI-22 vários municípios não operavam seus aterros de maneira adequada quando se trata do recobrimento dos resíduos. Exemplos da má prática estão os aterros de Tarabai, Marabá Paulista e Pirapozinho que apresentaram fortes odores sugerindo a falta de recobrimento por um longo período de dias. O recobrimento e raspagem diária são executados até que a vala atinja sua capacidade total, a partir de então uma cobertura final, de argila compactada e mais espessa é colocada.

O hábito de queimar resíduos remonta de um período em que não eram disponibilizados serviços de coleta e destinação de lixo. Oliveira (2015) ao fazer um resgate da história do Município de Anhumas conta que, em meados da década de 50, os munícipes tinham o hábito de queimar e/ou enterrar os resíduos orgânicos e provenientes da agricultura. A queimada 


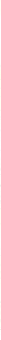

irregular de resíduos ocasiona o desperdício de materiais que poderiam ser reciclados, produzem uma fumaça tóxica e cancerígena além de emitir gases, como o dióxido de carbono $\left(\mathrm{CO}_{2}\right)$ que contribuem com o efeito estufa.

Um incentivo ao abandono da prática consiste no fato de ser um crime ambiental com pena entre 1 e 4 anos, além de multa. Diversos autores relatam que em muitos depósitos de lixo a prática ainda é realizada como é o caso de Tarabai onde ocorre a queima de resíduos hospitalares; em Presidente Epitácio acontece a queima de resíduos de podas; em lepê a queima de ossadas de animais e em todos estes, incluindo Sandovalina, ocorre a queima de resíduos em geral.

O documentário curta-metragem Ilha das Flores (1989) mostra a criação de porcos em meio ao depósito de lixo. Entretanto, a situação que parece peculiar e improvável acontece também no aterro de Pirapozinho, SP. A criação de animais na área do aterro foi constatada ainda no depósito de lixo do município de Tarabai, porém desta vez não porcos, mas gado.

Um dos pontos abordados pela Lei $12.305 / 2010$, no seu artigo $7^{\circ}$, está a valorização do catador (BRASIL, Lei n. 12.305 de 02 de ago. de 2010. Institui a Política Nacional de Resíduos Sólidos, Brasília, DF, ago. 2010). Esta iniciativa ajuda promover a inclusão de pessoas excluídas do mercado de trabalho, além de ser de extrema importância para que seja possível a efetiva reciclagem dos resíduos. A reciclagem efetiva minimiza a extração de recursos naturais não renováveis. Os municípios de Presidente Epitácio e Martinópolis contam com cooperativas locais onde é realizada a separação dos resíduos sólidos, constituindo um bem ambiental e social.

Após analisar cada um dos aspectos físicos e operacionais dos aterros presentes na UGRHI - 22 pode-se observar que o município de Presidente Venceslau, que já possui aterro sanitário desde 2007, ainda necessita de diversas adequações já que de acordo com Oliveira (2015), possui problemas de gestão. Um dos fatos que evidencia péssimas condições operacionais e de contaminação ambiental no local é a lagoa de armazenamento de chorume que em seu volume esgotado, vem a transbordar constantemente, trazendo riscos de contaminação do solo e de águas subterrâneas, como mostrado anteriormente na rede de interação da Figura 2.

Com destaque negativo entre os depósitos de lixo da Região do Pontal do Paranapanema, está o Município de Pirapozinho, o mesmo foi o único a ser classificado como lixão e interditado desde 2011 pela CETESB; apesar de ter continuado em uso até 12 de março de 2017, ou seja, seis anos depois. Em maio de 2017, retornando à visita de monitoramento no local onde funcionava o lixão, constatou-se que o mesmo havia encerrado efetivamente suas atividades (Figura 3). Atualmente o resíduo sólido urbano de Pirapozinho é armazenado em containers e 


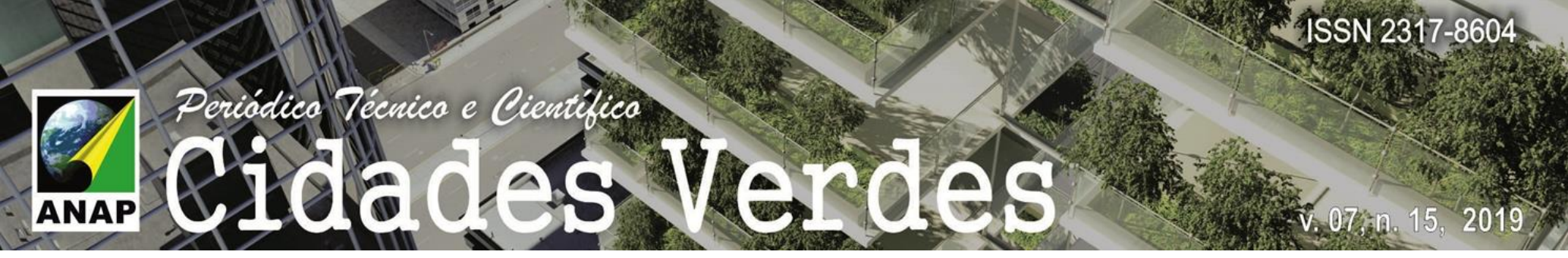

levado ao aterro sanitário particular presente no município de Quatá, SP, não pertencente à UGRHI-22, distando cerca de 100 quilômetros de Pirapozinho.

Figura 3 - Lixão Municipal de Pirapozinho
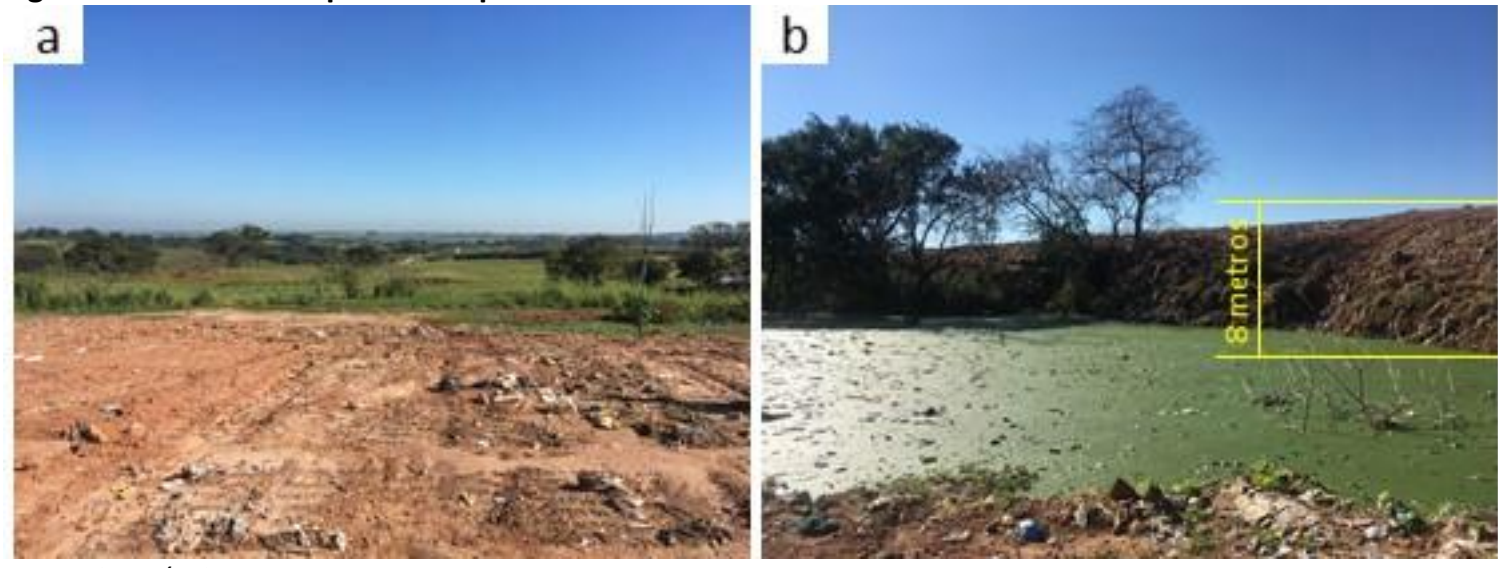

Fonte: Os próprios autores

Em visitas in loco, foi possível observar o encerramento das atividades, notou-se também que ainda não fora realizado o manejo adequado do local (Figura 3a) - com recobrimento dos resíduos com argila - apesar de haver maquinários trabalhando no local e que possivelmente poderão fazê-lo. Nesta mesma data a criação de gado, descrita anteriormente, foi vista no local, demonstrando a persistência e não pontualidade dos fatos.

Onde Osco (2016) observou uma nascente, pode-se observar a formação de uma grande lagoa alimentada pela então nascente, no entanto, a lagoa encontra-se totalmente eutrofizada (Figura 3b). A eutrofização acontece devido as altas concentrações de nutrientes presentes no solo do local, pela decomposição do lixo depositado ao longo das últimas décadas, e lixiviado para dentro da lagoa.

A lagoa formada é circundada por uma sequência de lixo depositados uns sobre os outros e compactados com o tempo, onde posteriormente eram abertas novas valas para destinação de mais lixo. Este ciclo é reflexo do uso de um local inapropriado e interditado pelo órgão ambiental.

Como resultado pode-se observar a alteração da paisagem e um incremento de cerca de 8 metros (de altura) de resíduo (Figura 3b) acumulado ao longo do tempo.

Hoje o Município de Pirapozinho, em consórcio com as cidades de Álvares Machado, Narandiba, Tarabai, Sandovalina e Estrela do Norte planejam construir um aterro sanitário do tipo trincheira. Estima-se que o custo seja de aproximadamente $\mathrm{R} \$ 650$ mil reais.

A escolha da área para implantação deste projeto foi feita em 2013, o licenciamento ambiental começou no segundo semestre de 2015 e a Licença de Instalação (L.I.) foi emitida pela CETESB em março de 2016. As negociações entre os municípios para efetivação do projeto continuam, porém a licitação para construção do aterro sanitário ainda não havia sido concretizada e nem há previsão de quando-acontecerá. Caso seja efetivada, cada município deverá implantar o programa de coleta seletiva e a reciclagem em suas cidades, o aterro será o primeiro na região a funcionar por meio de consórcio. 


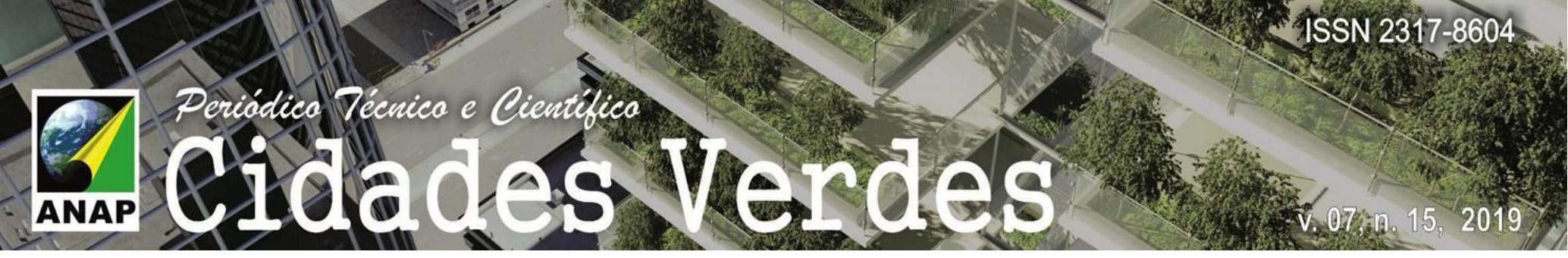

\section{CONCLUSÃO}

A Política Nacional dos Resíduos Sólidos instituída em 2010 representou um grande avanço social, ambiental e técnico com relação a correta destinação dos resíduos sólidos urbanos. Apesar das grandes dificuldades encontradas pelos municípios para se adequarem e atraso em atenderem as legislações vigentes, alguns avanços são observados e, talvez, com algum otimismo se possa perceber enxergar a chegada de uma sociedade preocupada com o hoje e com a manutenção do ambiente para as gerações futuras.

No Pontal do Paranapanema há muito o que ser feito para se possa deixar para traz a história de região marcada por degradar o ambiente natural. É importante seguir, porém consciente do passado explorador da terra e dos recursos naturais que faz com que sobre apenas $7 \%$ da vegetação nativa, rumo a um futuro de referência nas ações que constituem uma sociedade mais justa e preocupada com o meio ambiente.

Os aterros sanitários na região têm apresentado grande melhora nas condições de infraestrutura e operação. O maior exemplo disso é o fechamento do lixão de Pirapozinho que degradava e poluía o solo e a água do local. A lagoa eutrofizada mostra que a recuperação do ambiente não acontecerá tão logo, porém só o fato de cessarmos a degradação já nos deixa mais próximo de um ambiente saudável e recuperado.

Os trâmites entre municípios regionais em direção a construção de um aterro sanitário consorciado, o primeiro do tipo na região, também podem indicar uma mudança de paradigmas que nos levam a acreditar que a conscientização ambiental apesar de sofrer grande dificuldade de ser colocada em prática já tem mostrado resultados positivos.

Para o futuro que as ações em favor do meio ambiente e das pessoas não demorem 20 anos para se concretizarem e nos provem que, em paralelo as análises de custos existam as avaliações de danos ambientais que quando ponderados não só o melhor para imagem dos gestores públicos tenham relevância, mas sim o bem comum de uma sociedade de hoje e do futuro.

\section{AGRADECIMENTOS}

Agradecimentos à Coordenação de Aperfeiçoamento de Pessoal de Nível Superior (CAPES), pelo subsídio aos estudos, ao Programa de Pós Graduação em Meio Ambiente e Desenvolvimento Regional (PPGMADRE) da Universidade do Oeste Paulista (UNOESTE) e ao Instituto Federal de São Paulo (IFSP).

\section{REFERÊNCIAS}

ALMEIDA, U. F. DEPÓSITO INADEQUADO DE RESÍDUOS SÓLIDOS NO BAIRRO NOVO TEMPO II NO MUNICÍPIO DE ITUIUTABA - MG. 2018. 49 f. TCC (Graduação) - Curso de Geografia, Universidade Federal de Uberlândia, Ituiutaba, 2018. Disponível em: < https://repositorio.ufu.br/handle/123456789/22191 >. Acesso em: 26 set. 2018.

BENNETT, E. M.; PETERSON, G. D.; GORDON, L. J. Understanding relationships among multiple ecosystem services. Ecology Letters, [s.I.], v. 12, n. 12, p.1394-1404, 21 out. 2009. Wiley. http://dx.doi.org/10.1111/j.14610248.2009.01387.x.

BRASIL. Lei no 12.305: Política Nacional de Resíduos Sólidos (PNRS). Brasília, Distrito Federal, Brasil, ago. 2010.

BUENO, D. C. F.; LEAL, A. C. Geração e destinação dos resíduos sólidos domiciliares no Pontal do Paranapanema- São Paulo - Brasil. Fórum Ambiental da Alta Paulista, Presidente Prudente, v. 8, n. 12, p.159-176, 2012. 
CÂNDIDO, J. B.; SOUZA, P. A.; NERES, N. G. C.; GONÇALVES, D. S.; SOUZA, P. B. Diagnóstico ambiental e análise temporal dos impactos ambientais causados por um depósito de resíduos sólidos no município de Cariri do Tocantins - TO. Nucleus, [s.I.], v. 14, n. 1, p.125-140, 30 abr. 2017.

CESAR, A. C. G.; NASCIMENTO, L. F. C.; CARVALHO JUNIOR, J. A. Associação entre exposição ao material particulado e internações por doencas respiratórias em crianças. Revista de Saúde Pública, [s.I.], v. 47, n. 6, p.1209-1212, dez. 2013. FapUNIFESP (SciELO). http://dx.doi.org/10.1590/s0034-8910.2013047004713.

CETESB - Companhia de Tecnologia de Saneamento Ambiental. Manual ambiental: Procedimento para implantação de aterros sanitários em valas. Secretaria do Estado e Meio Ambiente: São Paulo, 2005.

CREMONEZ, F. E.; CREMONEZ, P. A.; FEROLDI, M.; CAMARGO, M P.; KLAJN, F. F.; FEIDEN, A. Avaliação de impacto ambiental: metodologias aplicadas no Brasil. Revista Monografias Ambientais, [s.l.], v. 13, n. 5, p.3821-3830, 16 nov. 2014. Universidad Federal de Santa Maria. http://dx.doi.org/10.5902/2236130814689.

FAGUNDES, D. C. Gerenciamento de resíduos sólidos urbanos em Tarumã e Teodoro Sampaio-SP. Dissertação (Mestrado em Geografia) Faculdade de Ciências e Tecnologia - UNESP, Presidente Prudente (SP). 137f. 2008.

FELíCIO, M. J. Desafios e Dilemas da Pesquisa em Ciências Ambientais. Revista Eletrônica do Curso de Geografia UFG/rej, Jataí, v. 1, n. 27, p.93-112, Jul/Dez 2016. Disponível em: < https://goo.gl/LDhF6c >. Acesso em: 08 out.

FELÍCIO, M. J. Contribuições aos Estudos da Questão Agrária no Pontal do Paranapanema. Campo-território: Revista de Geografia Agrária, Uberlândia, v. 11, n. 22, p.291-310, abr. 2016. Disponível em: < https://goo.gl/3FN2MM >. Acesso em: 08 out. 2017.

FERNANDES, L. R. Estudo da cobertura do lixão "Morávia" da cidade de Medellín, Colômbia. 2012. XXIII, 170 f., il. Dissertação (Mestrado em Geotecnia) — Universidade de Brasília, Brasília, 2012.

FIGUEIREDO, V. M. M. Aterro de Santo Tirso: Análise das metodologias de gestão e propostas de ação. $2013.91 \mathrm{f}$. Dissertação (Mestrado) - Curso de Mestrado Integrado em Engenharia do Ambiente, Universidade do Porto, S.I, 2013.

GARCIA, R. M.; TROMBETA, L. R.; NUNES, R.S.; GOUVEIA, I. C. M. C; LEAL, A.C. Mapeamento Geomorfológico da Unidade de Gerenciamento de Recursos Hídricos Pontal do Paranapanema, São Paulo, Brasil. In: IV Workshop Internacional sobre Planejamento e Desenvolvimento Sustentável em Bacias Hidrográficas, 2013, Presidente Prudente-SP. Anais do IV Workshop Internacional sobre Planejamento e Desenvolvimento Sustentável em Bacias Hidrográficas. Presidente Prudente: 4: 2013. v.4. p.1501-1514.

ILHA das Flores. Direção de Jorge Furtado. Porto Alegre: Casa de Cinema de Porto de Alegre, 1989. Son. color.

LOURENÇO, R. W.; SILVA, D. C. C.; SALES, J. C. A.; MEDEIROS, G. A.; OTERO, R. A. P. Metodologia para seleção de áreas aptas à instalação de aterros sanitários consorciados utilizando SIG. Ciência e Natura, [s.I.], v. 37, n. 3, p.122-139, 26 set. 2015. Universidade Federal de Santa Maria.

OLIVEIRA, R. C. Escolha de área para aterro sanitário em meios porosos: $\mathbf{O}$ caso do município de Anhumas (SP). Dissertação (Mestrado em Meio Ambiente e Desenvolvimento Regional) PPG em Meio Ambiente e Desenvolvimento Regional Faculdade - MMADRE - Universidade do Oeste Paulista - UNOESTE, Presidente Prudente (SP). $186 f .2015$.

OSCO, L. P. Degradação geoecológica por aterros de resíduos sólidos: Estudo aplicado a UGRHI - 22 e o Lixão de Pirapozinho - SP. Dissertação (Mestrado em Meio Ambiente e Desenvolvimento Regional) PPG em Meio Ambiente e Desenvolvimento Regional Faculdade - MMADRE - Universidade do Oeste Paulista - UNOESTE, Presidente Prudente (SP). 186f. 2016.

RIGUEIRA, D M G.; COUTINHO, S. L.; LEITE C. M. P.; SARNO, V. L. C.; ESTAVILLO, C.; CAMPOS, S.; DIAS, V. S.; BARROS, C.; CHASTINET, A. Habitat loss, environmental laws, and scientific knowledge: a proposal of evaluation criteria for requests for the suppression of vegetation. Revista Caititu - Aproximando Pesquisa Ecológica e Aplicação, [s.l.], v. 1, n. 1, p.21-42, 30 set. 2013. Nucleo de Pesquisa em Ecologia e Biodiversidade. http://dx.doi.org/10.7724/caititu.2013.v1.n1.d03. 


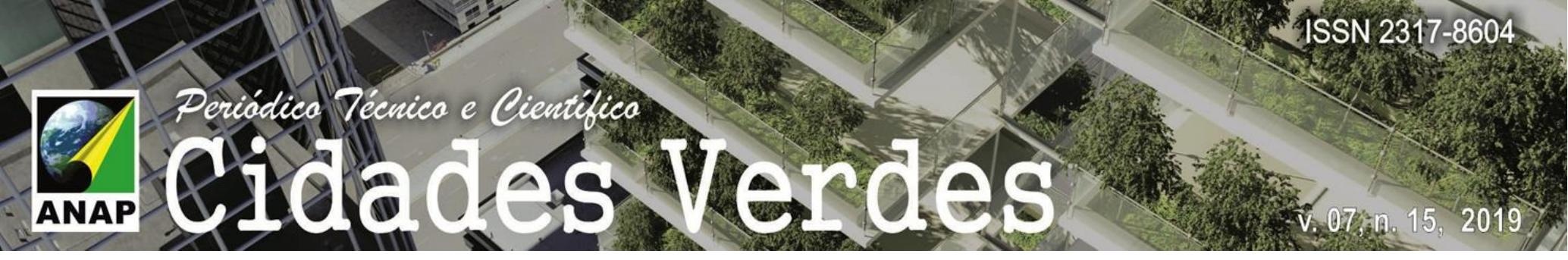

ROMAGNOLI, Iris. MAPEAMENTO DA VULNERABILIDADE E RISCOS DE CONTAMINAÇÃO DAS ÁGUAS SUBTERRÂNEAS NA REGIÃO DO PONTAL DO PARANAPANEMA (UGRHI-22) FRENTE A EXPANSÃO DO AGROHIDRONEGÓCIO. 85 f. Dissertação (Mestrado) - Curso de Agronomia, Universidade Estadual Paulista "Júlio de Mesquita Filho", Botucatu, 2018. Disponível em: < https://repositorio.unesp.br/handle/11449/154868 >. Acesso em: 26 set. 2018.

ROSS, J. L. S.; MOROZ, I. C. Mapa Geomorfológico do Estado de São Paulo escala 1:500.000. São Paulo: Laboratório de Geomorfologia, Departamento de Geografia FFLCH - USP/IPT/FAPESP, 1997

SANKOH, F; P.; YAN, X. TRAN, Q. Environmental and health impact of solid waste disposal in developing cities: a case study of Granville Brook dumpsite, Freetown, Sierra Leone. Journal of Environmental Protection, n. 4, p. 665-670, 2013.

SANTOS, F. M. Planejamento ambiental da Bacia Hidrográfica do Córrego Embirí - UGRHI Pontal do Paranapanema - São Paulo: inventário e diagnóstico. 2011. 108 f. TCC (Graduação) - Curso de Engenharia Ambiental da Faculdade de Ciências e Tecnologia - Fct/ Unesp, Departamento de Planejamento, Urbanismo e Meio Ambiente, Unesp, Presidente Prudente, 2011.

SHINZATO, M. P. B. Mobilização de poluentes no maciço de resíduos de lixão desativado. 2014. 196 f. Tese (Doutorado) - Curso de Engenharia Hidráulica e Saneamento, Universidade de São Paulo, São Carlos, 2014.

STUERMER, M. M.; BROCANELI, P.F.; VIEIRA, M.E.M. Os aterros sanitários desativados e o sistema de áreas verdes da cidade de São Paulo: Possibilidade de Integração. Labverde, São Paulo, v. 1, n. 2, p.11-29, jun. 2011.

World Health Organization. European Centre for Environment and Health. Methods of assessing risk to health from exposure to hazards released from waste landfills. Report from a WHO Meeting Lodz, Poland, 10 - 12 abr., 2000. Bilthoven; 2000. 